\title{
Pyroelectric polymer films for infrared detection
}

\author{
P JAYARAMA REDDY and M SIRAJUDDIN \\ Department of Physics, Sri Venkateswara University, Tirupati 517 502, India
}

\begin{abstract}
Some of the polymers have been recognised as potential materials for application in pyroelectric detectors because of their large and durable electric polarization. These materials are preferred over conventional ceramics due to their unique features which make them very sensitive and fast to the infrared radiation detection. The present paper deals with the special characteristics of polymer films, namely PVDF, PVC and PVF, their preparation and characterization and their pyroelectric behaviour.
\end{abstract}

Keywords. Pyroelectricity; polymer films; infrared detection.

\section{Introduction}

Pyroelectric detectors are of recent origin and are of special interest. These detectors, which are sensitive to the changes in detection temperature rather than to the absolute temperature itself, respond to radiation which is chopped, pulsed or otherwise modulated, but ignore steady background radiation. These are less sensitive compared to the photon detectors, but are capable of operating at ambient temperature and have consistent response over a long wavelength.

Since the discovery of piezo- and pyroelectricity in polyvinylidine fluoride (Kawai 1969; Bergman et al 1972), polymers are recognized as potentially important transducer materials. Polymers are preferred for pyroelectric detectors over conventional ceramics because of their unique features, namely, toughness, flexibility, low mechanical impedance, low density and ability to sustain to high fields. However, due to their relatively poor dimensional stability, the melting and softening temperatures are lower than ceramics. As a result when the temperature increases the pyroelectric activity deteriorates due to the increased segmental motion of the molecular chains which result in depolarization.

The change in polarization $\mathrm{dP}$ of a pyroelectric crystal due to the change in temperature $\mathrm{d} T$ is given by

$$
\mathrm{d} P=p \cdot \mathrm{d} T
$$

where $p$ is the pyroelectric coefficient of the crystal.

If the temperature change is caused by the absorption of infrared radiation, the observed pyroelectric effect is equivalent to the detection of incident radiation. The current $i$ in the external circuit is given by (Chynoweth 1956)

$$
i=A \frac{\mathrm{d} P}{\mathrm{~d} T} \frac{\mathrm{d} T}{\mathrm{~d} t}
$$

where $A$ is the area of the radiation receiving electrode and $\mathrm{d} T / \mathrm{d} t$ is the heating rate. 
Combining (1) and (2), we get

$$
p=i /[A(\mathrm{~d} T / \mathrm{d} t)]
$$

\section{Experimental}

\subsection{Film formation}

Solvent casting (Sirajuddin and Jayarama Reddy 1984) and laser evaporation (Sirajuddin and Jayarama Reddy 1984a, 1985) were employed in the present investigation to prepare the films of polyvinyl fluoride, polyvinylidene fluoride and polyvinyl chloride.

2.1a Solvent casting: The polymer materials were dissolved in a suitable solvent. The temperature of the solution was maintained at $60^{\circ} \mathrm{C}$ and the films of required thickness were obtained by immersing the glass substrates in the solution of known concentration and deposition time as described elsewhere (Sirajuddin et al 1984). Metal electrodes were vacuum evaporated before and after the film formation to characterize the films in sandwich configuration.

The films were dried in an oven at $100^{\circ} \mathrm{C}$ for about $48 \mathrm{hr}$ to evaporate the solvent present before the top electrode was deposited.

2.1b Laser evaporation: The polymer material was evaporated on glass substrates by laser radiation. A high power carbon dioxide laser of 60 watts was employed to evaporate polymer materials. The laser beam was allowed to pass through a zinc selenide window and reflected from gold-coated concave mirror onto the polymer. The pressure in the chamber was run down to $10^{-4}$ torr during the formation of films. The details of the evaporation technique were described elsewhere (Sirajuddin and Jayarama Reddy 1984a).

\subsection{Film characterization and measurement of pyroelectric currents}

The films were characterized by studying (i) infrared spectra in the range $2.5 \mu \mathrm{m}$ to $25 \mu \mathrm{m}$ using Perkin Elmer IR spectrophotometer, (ii) $\mathrm{x}$-ray diffraction profiles using Philips X-ray unit and (iii) molecular weight.

Capacitance and dielectric loss were measured using 4275A Hewlett Packard LCR meter. The resistivity was measured using $4140 \mathrm{~B}$ digital pA meter by applying a small voltage across the films.

The film thickness was determined using Stanton monopan microbalance by measuring the weight change of the substrate and assuming the density of the film and cross-checked by capacitance measurements.

The films sandwiched between $\mathrm{A} 1$ electrodes were poled by applying a constant electric field $\left(6 \times 10^{5} \mathrm{~V} / \mathrm{cm}\right)$ at a constant temperature $400 \mathrm{~K}$. The samples were cooled in the presence of the field and the pyroelectric currents were measured using the direct method similar to that used by Byer and Roundy (1972). The poled samples were heated to $363 \mathrm{~K}$ under short-circuit condition for about $2 \mathrm{hr}$ at a chamber pressure of $10^{-5}$ torr and then cooled to room temperature. The first thermal cycle, known as the depolarization current or irreversible cycle, is a measure of absorbed charges during poling process. The subsequent cycles, namely, heating the short-circuited samples at a 


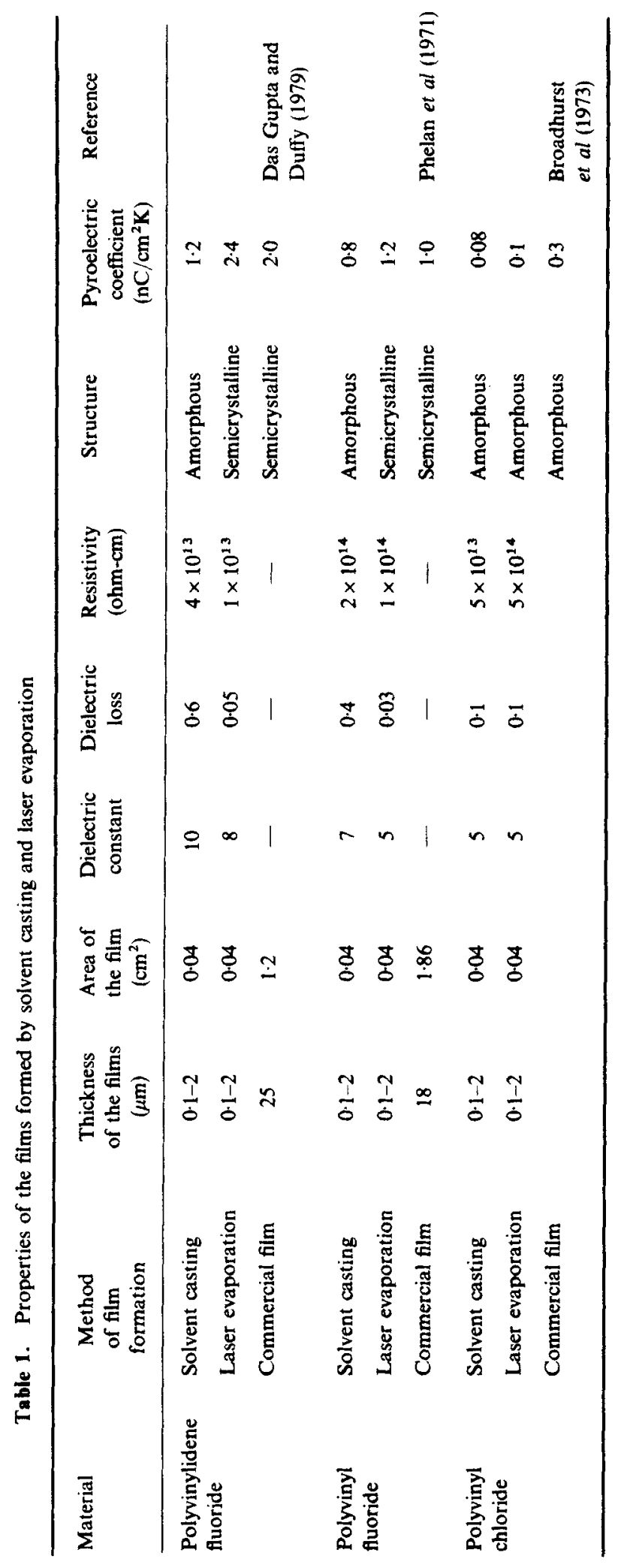


constant rate to a desired temperature and subsequent cooling were observed to give 'reversible' or 'true pyroelectric' currents. Pyroelectric currents were measured using 4140B digital pA meter. The temperature of the sample was monitored by a digital multimeter (Keithley 160B). The samples were gradually heated $(1 \mathrm{~K} / \mathrm{min})$ by circulating hot water. The temperature and pyroelectric currents were plotted on a $\mathrm{X}-\mathrm{Y} / \mathrm{t}$ recorder as a function of time.

\section{Results and discussion}

Table 1 gives the experimental results. The data of other workers wherever available are also given. The films obtained by laser evaporation are found to be uniform, pin holefree and crystalline with low dielectric loss and high pyroelectric coefficient compared to solvent cast films.

\subsection{IR and $x$-ray diffraction studies}

The infrared spectral studies reveal that the solvent cast films retain their chemical structure as that of the starting material whereas the laser-evaporated films have undergone structural changes. The changes were partial in the case of $\mathrm{PVF}_{2}$ and PVF whereas they were predominant in PVC. Figure 1 shows the infrared spectra of laserevaporated PVF films. The decrease in the intensity of the peak corresponding to the C-F bond suggests a partial decomposition of the polymer. A similar observation was made in $\mathrm{PVF}_{2}$. In the case of $\mathrm{PVC}$, the peaks corresponding to the $\mathrm{C}-\mathrm{C} 1$ stretchings and $\mathrm{C}-\mathrm{H}$ vibrations were found missing suggesting the decomposition of $\mathrm{PVC}$ during evaporation.

The $\mathrm{x}$-ray diffraction studies show that the solvent-cast films were amorphous whereas laser-evaporated $\mathrm{PVF}_{2}$ and PVF films were crystalline. Figure 2 shows the diffraction pattern of typical $\mathrm{PVF}_{2}$ films prepared by both the techniques. Because of their crystallinity the laser-evaporated films exhibited high pyroelectric activity in spite of partial structural deviation.

\subsection{Molecular weight measurement}

The molecular weight of the films was determined using gel permeation chromatography and the results are shown in table 2 . It was found that laser evaporation

Table 2. Molecular weight comparison of laser evaporated films with starting material

\begin{tabular}{llclll}
\hline Material & $\begin{array}{l}\text { Number average angstrom } \\
\text { size extended chain length }\end{array}$ & & \multicolumn{2}{l}{$\begin{array}{l}\text { Number average molecular } \\
\text { weight }\end{array}$} \\
\cline { 2 - 3 } & $\begin{array}{l}\text { Starting } \\
\text { material }\end{array}$ & $\begin{array}{c}\text { Laser- } \\
\text { evaporated }\end{array}$ & & $\begin{array}{l}\text { Starting } \\
\text { material }\end{array}$ & $\begin{array}{c}\text { Laser- } \\
\text { evaporated }\end{array}$ \\
\hline PVF $_{2}$ & 2,500 & 360 & & 20,400 & 5,420 \\
PVF & 1,800 & 250 & & 15,000 & 5,300 \\
PVC & 1,500 & 100 & 12,000 & 3,500 \\
\hline
\end{tabular}




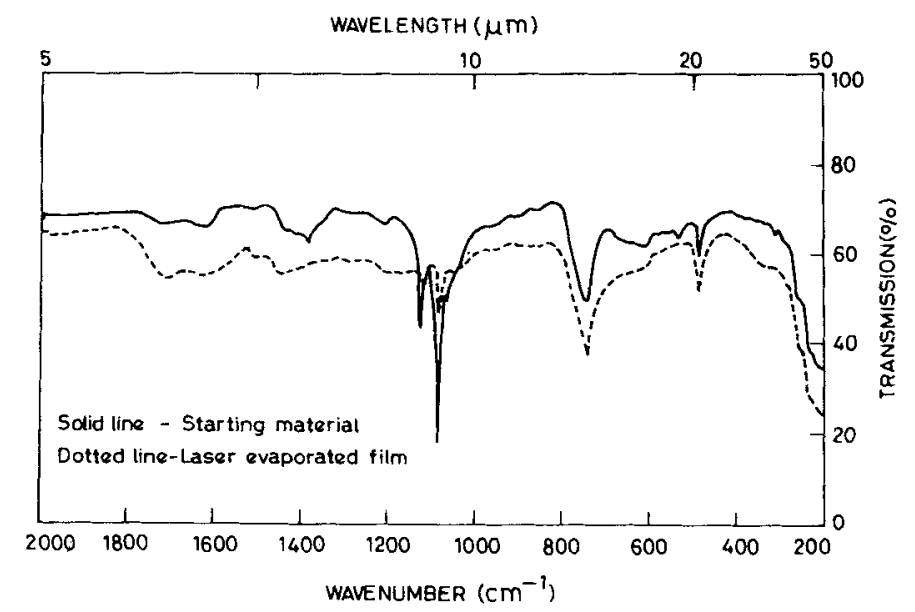

Figure 1. IR spectra of polyvinyl fluoride film.

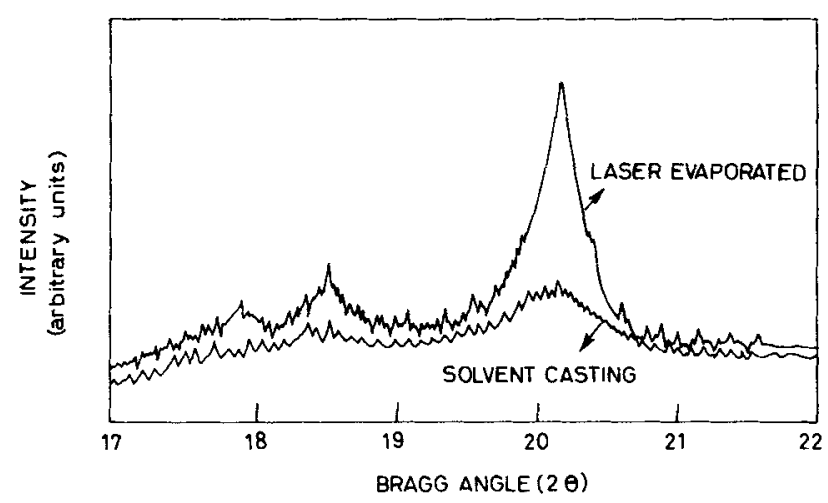

Figure 2. X-ray diffraction pattern of $\mathrm{PVF}_{2}$ film ( $2 \mu \mathrm{m}$ thick).

drastically reduced the molecular weight of the polymer. The shortening of the chain length of the laser-evaporated films suggest that the materials transferred into vapour phase rather than as solid particles during evaporation.

\subsection{Pyroelectric coefficient}

The pyroelectric coefficient of the films was derived from the pyroelectric current vs temperature plot using equation (3).

It was observed that the polarity of the short circuit current in these films was opposite to that of the charging current suggesting that the pyroelectric activity might be due to the dipolar orientation (Nakamura and Wada 1971). The residual polarization obtained by integrating the liberated charges during the pyroelectric current measurement after the first thermal cycling of these films are shown in table 3 . From the rigid dipolar model (Lines and Glass 1977) the polarization induced in these 
Table 3. A comparison of experimental and theoretical values of residual polarization in vinyl halogen polymers

\begin{tabular}{lcc}
\hline \multirow{2}{*}{ Polymer } & \multicolumn{2}{c}{ Residual polarization $\left(\mu \mathrm{C} / \mathrm{cm}^{2}\right)$} \\
\cline { 2 - 3 } & $\begin{array}{c}\text { Laser- } \\
\text { evaporated } \\
\text { films }\end{array}$ & $\begin{array}{c}\text { From the } \\
\text { rigid dipolar } \\
\text { model }\end{array}$ \\
\hline PVF $_{2}$ & 0.5 & 0.3 \\
PVF & 0.3 & 0.1 \\
PVC & 0.1 & 0.08 \\
\hline
\end{tabular}

materials was evaluated and shown in table 3 for comparison with observed values. It is seen that the observed values are significantly higher than the evaluated values. This suggests that the injection of charge carriers during poling may also be contributing to the pyroelectric activity in these materials. The studies on PVF films with asymmetrical electrode configuration (Jayarama Reddy 1984) also revealed that the polarization in these films was due to the injection of charge carriers during poling process together with dipolar orientation. The fact that injection of charge carriers was taking place further supported by the steady state current voltage characteristics revealed Schottky emission in these films (Sirajuddin and Jayarama Reddy 1984b). Similar conclusions were also drawn by Pfister et al (1973) and Takahashi et al (1977) in studying $\mathrm{PVF}_{2}$ films with different electrode configurations. The Schottky type conduction in PVC (Rastogi and Chopra 1975) and the effect of metal electrodes on the depolarization currents of PVC electrets (Talwar and Behari 1981) also support the contribution of injection of charge carriers from the electrodes to the polarization of the sample. These observations suggest that the pyroelectricity in these materials can be accounted by taking both the injection of charge carriers and the dipolar orientation.

\section{Conclusions}

(i) Laser evaporation appears to give uniform and pin hole-free polymer films compared to solvent casting method, (ii) Laser evaporated films of $\mathrm{PVF}_{2}$ and $\mathrm{PVF}$ are found to be crystalline with low dielectric loss and high pyroelectric coefficient, and are comparable to commercial polymer films in performance. (iii) Laser evaporated films of PVC are amorphous and suffered degradation during film formation and (iv) the origin of pyroelectricity in these films can be accounted by taking both the space charge model and dipolar orientation.

\section{Acknowledgement}

The authors are grateful to the Department of Science and Technology, New Delhi for providing financial assistance to carry out the present work under SERC project. 


\section{References}

Bergman J G, Crane G R, Ballman A A and O'Bryan H 1972 Appl. Phys. Lett. 21497 Broadhurst M G, Harris W P, Mopsik F I and Malmberg C G 1973 Polymer Reprints 14820 Byer R L and Roundy C B 1972 Ferroelectrics 3333

Chynoweth A G 1956 J. Appl. Phys. 2778

Das-Gupta D K and Duffy J S 1979 J. Appl. Phys. 50561

Jayarama Reddy $\mathbf{P} 1984$ Proc. 2nd All India Conf. on Thin film State Phenomena, IIT, Madras Kawai M 1969 Jpn. J. Appl. Phys. 8975

Lines A E and Glass A M 1977 Principles and applications of ferroelectrics and related materials Oxford: Clarendon) p. 608

Nakamura K and Wada Y 1971 J. Polym. Sci. 9161

Phelan Jr R J, Mahler R J and Cook A R 1971 Appl. Phys. Lett. 19337

Pfister G, Abkowitz M and Crystal R G 1973 J. Appl. Phys. 442064

Rastogi A C and Chopra K L 1975 Thin Solid Films 2661

Sirajuddin M, Kesava Raju V and Jayarama Reddy P 1984 Phys. Status Solidi A81 K-37

Sirajuddin M and Jayarama Reddy P 1984a Proc. Natl. Symp. Inst. Kashmir

Sirajuddin M and Jayarama Reddy P 19846 J. Phys. Chem. Solids (Communicated)

Sirajuddin M and Jayarama Reddy P 1985 Thin Solid Films 124149

Takahashi K, Lee H, Salomon R E and Labes M M 1977 J. Appl. Phys. 484697

Talwar 1 M and Behari S 1981 Proc. Nucl. Phys. Solid State Phys. Symp. (Bombay: Bhabha Atomic Res. Centre) C24615 